authors' own prejudices have been included, without any reasoned arguments as justification. For instance comment is made that the level of financial support for basic research in the United States and United Kingdom is inadequate, but no discussion is advanced as to how anyone may judge what is adequate support for basic or any other form of research.

As an overall criticism of the book it must be emphasised that the authors have unnecessarily allowed some of their own unsupported opinions to be included when they would probably retain a receptive audience by being more independent. This comment applies to the authors' serious and repeated attack on pedigree breeders throughout the book. Whilst these breeders may be obstructive to progress it is surely better to gain their attention and confidence in order to change their attitude rather than to ostracise them. It is most likely that many pedigree breeders starting to read this book will shut it again within a few pages because of its derogatory comments. The authors' opinion is that a spirited attack on the persons and factors which they consider are the barriers to improvement is the best way of provoking discussion and creating conditions in which change is easier. Many people will disagree with the authors.

In conclusion it must be repeated that this is a surprising though excellent and much needed book which because of its depth and width of subject matter should be read by all those interested in any aspect of animal and perhaps plant breeding and by those interested in the impact of science on society. It is certain to provoke further thought, discussion and research on problems which are only just being explored.

John C. Bowman.

\title{
PROGRAMMED GENETICS
}

INTRODUCTION TO GENETICS: SCIENCE OF HEREDITY. A. J. S. McMillan. Pergamon Press. 25s.

This book is a programmed text. There is much evidence to show that programmed texts have certain educational advantages compared with conventional texts, particularly with regard to the less able student. Many teachers reserve judgement about their merits, however, partly, no doubt, because of their novelty and partly also, because of the often vigorous promotion campaign that has accompanied their appearance on the market. It is important, therefore, that programmed texts should be of the highest possible quality. The writing of such texts poses special difficulties because it requires skills other than the mastery of the subject matter in question. Many of the texts now appearing on bookshelves, including the present one, are written by persons who though expert in writing in this form are not necessarily expert in the subject they seek to teach.

The present volume, written for sixth-formers, is in the form of a linear programme, the material being organised into 382 frames. There are chapters on the laws of heredity, chromosomes and genes, chromosome theory and Mendelism, mitotic and meiotic accidents, gene action and plant breeding. There is a glossary of terms and the text includes revision questions as well as those connecting successive frames.

The book rather neatly illustrates the special difficulties encountered with programmed texts. Thus, the subject matter is, as it should be, well organised and clearly explained. But equally there are places in the exposi- 
tion which suggest that the author has not quite achieved a thorough understanding of the subject. Thus, in respect of Mendel's peas, we are told that it takes at least two generations of self-fertilisation in order to establish whether or not a tall individual is true-breeding for this character (frame 51 ). Again, in frame 146 and thereafter, the association of two chromatids at first meiotic anophase are referred to as bivalents, a term usually restricted to the association of homologous chromosomes at diplotene, diakinesis and metaphase. Such errors could have been removed from the text had a competent geneticist been asked to read it before publication.

It is less easy to understand, however, how infuriating errors of other types have remained undetected. Thus frame 43 shows a diagram which indicates that all tall $F_{2}$ pea plants in Mendel's experiment segregate in $F_{3}$, which is in flat contradiction to the written evidence of the previous frame. There are also a number of "slips" and other typographical errors. Yet this text, as is common practice, was subjected to a validation test before publication, though we are provided with insufficient details of this test in respect to numbers of students and their educational attainment. It is, therefore, difficult to take such a validation certificate seriously.

Despite these criticisms this book, when it is revised, will be a very welcome addition to the ranks of inexpensive introductory texts on genetics and I am disappointed that it has not been more carefully produced.

M. J. Lawrence.

\section{COMPLEMENTATION: FACTS, THEORIES AND SPECULATIONS}

GENETIC COMPLEMENTATION. J. R. S. Fincham. W. A. Benjamin Inc., New York, 1966. Pp. xiit143. $\$ 9.65$.

This book is a concise summary of the extensive literature on genetic complementation written for advanced students, research workers and those who teach biochemical genetics. It opens with a comparative account of the genetic systems which have been used for complementation studies in higher organisms, fungi, bacteria and bacteriophages. In spite of the great diversity of systems used in these studies the author rather surprisingly concludes that they all give equivalent information, at least at the qualitative level.

In the next two chapters the approach is basically historical. We are taken from the earliest definition of a gene to the one cistron-one polypeptide chain hypothesis in chapter 2, and from the breakdown of the original cistron concept to the emergence of the operon hypothesis in chapter 3 . In chapter 2 and for the remainder of the book the term gene is used as synonymous with cistron.

The two most favoured of the possible mechanisms of interallelic complementation, namely, reassortment of gene products and hybrid protein production, are considered in chapter 4 . Both the evidence presented, and the author, clearly favour the latter interpretation, the superiority of the hybrid protein being explained by the correction of the conformation of the protein molecule.

Chapter 5 is concerned with complementation maps and their interpretation. Following a survey of the incidence of linear, circular and more complex maps and their structural meaning, the author takes a firm line about the value of the effort that is put into the construction of elaborate comple- 